\title{
PERBANDINGAN HASIL BELAJAR DISCOVERY LEARNING BERBASIS PROBLEM SOLVING DAN GROUP INVESTIGATION BERBASIS PROBLEM SOLVING PADA PEMBELAJARAN METODE NUMERIK
}

\author{
Ira Vahlia ${ }^{1}$ \\ Rina Agustina ${ }^{2}$ \\ ${ }^{1,2}$ Pendidikan Matematika FKIP Universitas Muhammadiyah Metro \\ Email: iravahlia768@yahoo.co.id ${ }^{1)}$ \\ aasyiqun1212@gmail.com ${ }^{2)}$
}

\begin{abstract}
Discovery learning is a learning that involves students in the process of mental activity through a brainstorm, to discuss, and try it yourself, so that children can learn to be independent. Resulting in the discovery-based learning problem solving is to let children discover things on their own and group investigation that emphasizes problem solving based on a debriefing activities and student participation. The classes drawn into the sample, the class as a class given control based discovery learning and problem solving one class another group investigation given learning-based problem solving. Data analysis techniques in this study using $T_{\text {tes. }}$ From the results of this study concluded that: (a) In the first experiment class that implements learning model-based problem solving group investigation obtained average value of learning outcomes at 73.10 while the experimental class II implementing discovery-based learning problem solving obtained average value postest average of 66.55. (b) There are significant differences between the results of student learning in the class that implements the discovery-based learning and problem solving class that implements the learning model based problem solving group investigation. Student results in learning problem solving based group investigation better on the class that implements the model-based discovery learning problem solving.
\end{abstract}

Keywords: discovery learning, group investigation, learning numerical methods, problem solving

\section{PENDAHULUAN}

Salah satu mata kuliah wajib pada program studi pendidikan matematika adalah metode numerik. Pada pembelajaran metode numerik, mahasiswa diajak untuk dapat menyelesaikan persoalan - persoalan matematis yang penyelesaiannya sulit didapatkan dengan menggunakan metode analitik, antara lain: akarakar persamaan polinom, sistem persamaan lanjar, nilai integral, persamaan infferensial, interpolasi polinom, turunan numerik, integrasi numerik, dan lain-lain.

Menurut Setiawan, A (2006:25) Metode Numerik adalah 
teknik-teknik yang digunakan untuk memformulasikan masalah matematis agar dapat dipecahkan dengan operasi perhitungan. Metode numerik secara umum merupakan salah satu mata kuliah yang diajarkan di jurusan pendidikan matematika maupun matematika murni. Metode Numerik dianggap penting karena mengajarkan mahasiswa memecahkan suatu kasus dengan memakai berbagai cara dan permodelan. Terlebih, dalam mata kuliah ini juga mengharuskan mahasiswanya untuk cekatan dan aktif dalam memaksimalkan teknologi. Yang termasuk program paket numerik yang digunakan untuk menyelesaikan masalah matematika. Metode numerik merupakan alat untuk memecahkan masalah matematika yang sangat handal. Banyak permasalahan teknik yang mustahil dapat diselesaikan secara analitik karena sering dihadapkan pada sistem-sistem persamaan yang besar dan tidak linear serta cakupan yang kompleks dapat diselesaikan dengan metode numerik.

Dalam pembelajaran, dosen diharapkan mampu memilih model pembelajaran yang sesuai dengan materi yang diajarkan. Salah satu model pembelajaran inovatif yang dapat digunakan adalah model pembelajaran discovery learning berbasis problem solving. Model pembelajaran discovery learning berbasis problem solving merupakan cara untuk mengembangkan belajar mahasiswa aktif dengan menemukan sendiri, menyelidiki sendiri, maka hasil yang akan diperoleh akan tahan lama dalam ingatan, tidak mudah dilupakan mahasiswa. Dalam model pembelajaran ini mahasiswa menemukan dan mengkonstruksi sendiri sehingga menemukan konsep baru yang belum pernah diketahui sebelumnya. Selain itu, memberikan kesempatan kepada mahasiswa untuk dapat menggunakan kemampuan bernalarnya. Pada model ini pembelajaran dimulai dengan menyajikan permasalahan nyata yang penyelesaiannya membutuhkan kerjasama diantara mahasiswa.

Hamdani (2010: 184) menyatakan bahwa "Discovery (penemuan) adalah proses mental siswa mengasimilasikan suatu konsep atau suatu prinsip. Adapun proses mental, misalnya mengamati, menjelaskan, mengelompokkan, membuat kesimpulan, dan sebagainya. Konsep, misalnya bundar, segitiga, demokrasi, energi, dan sebagainya.Sedangkan prinsip, misalnya setiap logam apabila dipanaskan memuai."

Menurut Lee (2010: 294), dalam proses pembelajaran siswa dapat memecahkan masalah dengan diberi kesempatan untuk 
menghadapi situasi realitas dalam kehidupan sehari-hari. Dengan model pembelajaran problem solving, siswa dapat menggeneralisasi dan mendapatkan solusi dari permasalahan.

Dari pendapat di atas dapat disimpulkan bahwa pembelajaran discovery berbasis problem solving ialah suatu pembelajaran yang melibatkan mahasiswa dalam proses kegiatan mental melalui tukar pendapat, dengan berdiskusi, membaca sendiri dan mencoba sendiri, agar mahasiswa dapat belajar sendiri.

Langkah - langkah pembelajaran dengan model discovery berbasis problem solving pada penelitian ini sebagai berikut:
1. Menentukan
tujuan pembelajaran.

2. Melakukan identifikasi karakteristik mahasiswa.

3. Memilih sub pokok bahasan.

4. Menentukan topik-topik yang harus dipelajari mahasiswa secara induktif (dari contohcontoh generalisasi).

5. Adanya masalah yang jelas untuk dipecahkan. Masalah ini harus tumbuh dari mahasiswasesuai dengan taraf kemampuannya.

6. Mencari data yang dapat digunakan untuk memecahkan masalahyang muncul. Misalnya dengan jalan membaca buku-buku, meneliti, bertanya, danberdiskusi.

7. Menetapkan jawaban sementara dari masalah tersebut. Dugaan jawaban tentu sajadidasarkan pada data yang telah diperoleh pada langkah sebelumnya.

8. Menguji kebenaran jawaban sementara tersebut sehingga benar-benar yakin bahwa jawaban tersebut cocok.

9. Mengembangkan bahan-bahan belajar yang berupa contohcontoh, ilustrasi, tugas dan sebagainya untuk dipelajari mahasiswa.

10. Menarik kesimpulan. Artinya mahasiswa harus sampai pada kesimpulan terakhir tentang jawaban dari masalah tadi.

Model pembelajaran lain yang dapat digunakan dalam pembelajaran metode numerik adalah model pembelajaran group investigation berbasis problem solving. Model group investigation adalah salah satu model pembelajaran kooperatif dimana anggota kelompok mengambil bagian dalam merencanakan berbagai dimensi dan tuntutan dari proyek mereka.

Menurut Silver (2007:11-12) problem solving memiliki beberapa pengertian.Pertama, problem solving ialah pengajuan soal sederhana atau perumusan ulang suatu soal yang ada dengan beberapa perubahan agar lebih 
sederhana dan dapat dipahami dalam rangka menyelesaikan soal yang rumit. Kedua, perumusan soal yang berkaitan dengan syaratsyarat pada soal yang telah diselesaikan dalam rangka mencari alternatif penyelesaian. Sedangkan pengertian yang ketiga, perumusan soal atau pembentukan soal dari suatu situasi yang tersedia, baik dilakukan sebelum, ketika, atau setelah menyelesaikan suatu soal.

Menurut Thobroni (2011: 295) "model group investigation melibatkan siswa sejak perencanaan, baik dalam menentukan topik maupun cara untuk mempelajari melalui ivestigasi. Model ini menuntut siswa untuk memiliki kemampuan yang baik dalam berkomunikasi maupun dalam keterampilan proses berkelompok (group process skill)." Dalam group investigation, siswa dituntut untuk lebih aktif dalam mengembangkan sikap dan pengetahuannya tentang matematika sesuai dengan kemampuan masing-masing sehingga mereka mendapat pengertian yang lebih bermakna tentang penggunaan matematika di berbagai bidang. Sehingga akan berdampak baik bagi siswa dengan memberikan kesempatan yang lebih besar dengan adanya transfer pengetahuan.

Dari pendapat di atas, model group investigasion berbasis problem solving melibatkan mahasiswa sejak perencanaan, baik dalam menentukan topik maupun cara untuk mempelajarinya melalui investigasi. Model pembelajaran ini menuntut mahasiswa untuk memiliki kemampuan yang baik dalam berkomunikasi maupun dalam keterampilan proses kelompok.

Dalam penelitian ini, proses pembelajaran dengan model group investigation berbasis problem solving dilakukan dengan langkah-langkah sebagai berikut:

1. Mahasiswa mencari beberapa sumber dan mengusulkan sejumlah topik.

2. Mahasiswa dikelompokkan secara heterogen dengan 4-6 siswa tiap kelompok;

3. Mahasiswa bergabung dengan kelompoknya untuk mempelajari topik yang telah mereka pilih.

4. Tiap kelompok membagi tugas atau sub topik agar tiap anggota kelompok dapat berpartisipasi aktif;

5. Mahasiswa secara berkelompok diminta mengajukan pertanyaan dari soal yang sesuai situasi atau informasi yang dibuat oleh dosen dan mahasiswa yang bersangkutan harus mampu menyelesaikannya.

6. Setiap kelompok mendiskusikan hasil investigasi dari tiap individu untuk membuat kesimpulan akhir; 
7. Salah satu kelompok mempersentasikan hasil diskusinya;

8. Dosen memberikan latihan pada mahasiswa dan dikerjakan secara individu.

\section{METODE PENELITIAN}

Penelitian ini termasuk kelompok jenis penelitian eksperimental semu (quasi eksperimental) karena penelitian tidak mungkin untuk mengontrol semua variabel yang ada. Variabel dalam penelitian ini terdiri dari:

1. Variabel bebas : model pembelajaran discovery berbasis problem solving dan model pembelajaran group investigation berbasis problem solving.

2. Variabel terikat : hasil belajar

Penelitian ini dilaksanakan di Universitas Muhammadiyah Metro Propinsi Lampung pada program studi Pendidikan Matematika. Waktu penelitian dilaksanakan pada semester ganjil tahun akademik 2015/2016. Populasi dan sampel dalam penelitian ini adalah mahasiswa program studi pendidikan matematika semester tujuh yang mengikuti mata kuliah metode numerik pada semester ganjil tahun akademik 2015/2016.

Urutan-urutan kegiatan yang dilakukan adalah:

1. Melakukan observasi di mata kuliah metode numerik semester 7 meliputi observasi objek penelitian, proses

pembelajaran dan fasilitas yang dimiliki.

2. Memberikan perlakuan dengan menggunakan model pembelajaran discovery berbasis problem solvingpada kelas eksperimen pertama, group investigation berbasis problem solving pada kelas eksperimen kedua.

3. Memberikan tes prestasi belajar.

4. Mengolah danmenganalisis data penelitian.

5. Menguji hipotesis dan mengambil kesimpulan.

Teknik Pengumpulan data dalam penelitian ini menggunakan metode tes.Dalam penelitian ini bentuk tes yang digunakan essay yang terdiri dari 5 butir soal.Sebelum digunakan untuk mengambil data penelitian, instrumen tersebut diuji terlebih dahulu dengan uji validitas isi. Berikut langkah-langkah validitas isi:

1. Menyusun soal tes

2. Meminta validasi soal tes kepada tiga orang validator.

3. Merevisi soal berdasarkan saran validator.

4. Memvalidasi soal tes.

Teknik pengumpulan data dalam penelitian ini, sebagai berikut: 1. Melakukan observasi di mata kuliah metode numerik semester 7 meliputi observasi objek penelitian, proses pembelajaran dan fasilitas yang dimiliki. 
2. Melaksankan pembelajaran discovery learning berbasis problem solving

3. Memberikan tes prestasi belajar.

4. Mengolah dan menganalisis data penelitian.

5. Menguji hipotesis dan mengambil kesimpulan.

Uji hipotesis dalam penelitian ini menggunakan uji $\mathrm{T}_{\text {tes. }}$ Sebelum melakukan uji hipotesis, data akan di uji prasayat yang meliputi uji normalitas dengan metode liliefors dan uji homogenitas dengan uji Barlett.

\section{HASIL DAN PEMBAHASAN}

Data hasil penelitian ini meliputi data hasil belajar siswa pada masing-masing kelas, yaitu kelas eksperimen I yang menerapkan model pembelajaran Group Investigation berbasis Problem Solving dan kelas Eksperimen II yang menerapkan model pembelajaran Discovery Learning berbasis Problem Solving. Data yang dianalisis diperoleh dari nilai mid semester pada pertemuan ke-8 perkuliahan, nilai postest yang diberikan pada pertemuan ke-16 yaitu di akhir perkuliahan.

\section{a. Hasil Uji Coba Instrumen}

Uji coba instrumen ini dilakukan pada mahasiswa pendidikan matematika semester 7 yang mengikuti pembelajaran metode numerik dengan jumlah mahasiswa sebanyak 56 orang. Dalam penelitian ini, kelas A terdiri dari 27 mahasiswa sebagai kelas ekperimen dengan Group Investigation berbasis Problem Solving dan kelas terdiri dari 29 mahasiswa yang diberi pembelajaran Discovery Learning Berbasis Problem Solving.

Validitas instrumen dalam penelitian ini menggunakan validitas isi. Validator yang digunakan adalah 3 orang dosen pendidikan matematika, yaitu: Swaditya Rizki, M. Sc. (Ketua Program Studi Pendidikan Matematika UM Metro), Nurul Farida, M. Pd. (Dosen Pendidikan Matematika UM Metro), Rosida Rakhmawati, M. Pd. (Dosen Pendidikan Matematika IAIN Lampung).

Reliabilitas terhadap butirbutir instrumen dianalisis dengan teknnik Alpha Cronbach. Perhitungan reliabilitas sebanyak 5 soal diperoleh hasil $r X Y=$ 0.6487 . Untuk dapat mengetahui reliabilitas instrument, perlu dicari nilai tabel $\mathrm{r}$ Product Moment dengan derajat kebebasan, $\mathrm{dk} n-$ $1=30-1=29$, serta signifikansi $5 \%$, diperoleh $\mathrm{r}$ tabel $=0.367$. jika $r X Y>r$ tabel berarti reliabel, dan sebaliknya jika $r X Y<r$ tabel berarti tidak reliabel. Karena $0.6487>0.367$, dengan demikian instrumen memiliki representasi reliabel.

Data kemampuan awal matematika siswa diperoleh dari nilai Mid Semester. Deskripsi data kemampuan awal matematika siswa pada kelas eksperimen. 
Tabel 1. Deskripsi Data Kemampuan Awal Matematika Siswa

\begin{tabular}{|l|c|c|c|c|c|}
\hline \multicolumn{1}{|c|}{ Model } & $\boldsymbol{n}$ & $\begin{array}{c}\text { Nilai } \\
\text { Min }\end{array}$ & $\begin{array}{c}\text { Nilai } \\
\text { Maks }\end{array}$ & Rerata & $\begin{array}{c}\text { Standar } \\
\text { Deviasi }\end{array}$ \\
\hline Group Investigation & 27 & 60 & 90 & 73,15 & 8,33 \\
\hline Discovery Learning & 29 & 55 & 85 & 66,51 & 20,33 \\
\hline
\end{tabular}

Uji prasyarat untuk uji keseimbangan meliputi uji normalitas populasi dan uji homogenitas variansi populasi.
Uji normalitas populasi ini dilakukan sebanyak dua kali menggunakan metode Lilliefors disajikan dalam Tabel 2 berikut.

Tabel 2. Rangkuman Hasil Uji Normalitas Populasi Terhadap Data Kemampuan Awal Matematika Mahasiswa

\begin{tabular}{|l|c|c|c|c|}
\hline \multicolumn{1}{|c|}{ Kelas } & $\boldsymbol{n}$ & $\boldsymbol{L}_{\boldsymbol{h i t}}$ & $\boldsymbol{L}_{\mathbf{0 , 0 5} \boldsymbol{n}}$ & Keputusan Uji \\
\hline Discovery & 27 & 0,1535 & 0,1730 & $\mathrm{H}_{0}$ tidak ditolak \\
\hline Group Investigation & 29 & 0,1499 & 0,1610 & $\mathrm{H}_{0}$ tidak ditolak \\
\hline
\end{tabular}

Sampel pada kelas discovery learning mempunyai nilai $L_{\text {hit }}$ sebesar 0,1535 dan group investigateon $L_{\text {hit }}$ sebesar 0, 1499. Hasil $L_{h i t}$ yang diperoleh kurang dari $L_{0,05 ; n}$. Dengan demikian, dapat disimpulkan bahwa sampel berasal dari populasi yang berdistribusi normal.

Dengan taraf signifikansi 0,05 , berikut hasil uji homogenitas variansi populasi menggunakan uji Bartlett disajikan pada Tabel 3.

\section{Tabel 3. Hasil Uji Homogenitas Variansi Populasi Terhadap Data Kemampuan Awal Matematika Siswa}

\begin{tabular}{|c|c|c|c|c|}
\hline \multicolumn{1}{|c|}{ Sampel } & $\boldsymbol{k}$ & $\chi^{2}{ }_{\text {hit }}$ & $\chi^{2}{ }_{0,05 ; 2}$ & $\begin{array}{c}\text { Keputusan } \\
\mathbf{U j i}\end{array}$ \\
\hline $\begin{array}{l}\text { Kelas Discovery dan } \\
\text { Group Investigation }\end{array}$ & 2 & 0,0400 & 5,9910 & $H_{0}$ diterima \\
\hline
\end{tabular}

Berdasarkan hasil uji homogenitas variansi populasi terhadap data kemampuan awal matematika siswa, diperoleh nilai $\chi_{\text {hit }}^{2}$ sebesar 0,04 dan $\chi_{0,05 ; 2}^{2}$ sebesar 5,9910. Hai ini berarti pada taraf signifikansi 0,05 nilai $\chi^{2}$ hit kurang dari $\chi_{0,05 ; 2}^{2}$.Dengan demikian, $H_{\mathrm{o}}$ tidak ditolak dan diperoleh populasi mempunyai variansi yang sama (homogen).

Setelah didapatkan data distribusi normal dan homogenitas, maka selanjutnya dilakukan uji keseimbangan. 


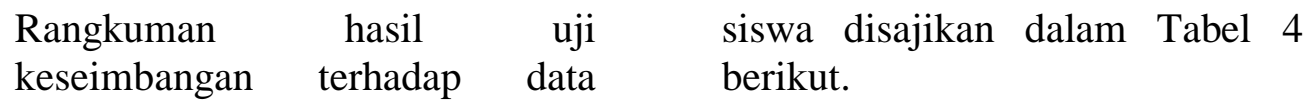
kemampuan awal matematika

Tabel 4. Hasil Uji Keseimbangan Terhadap DataKemampuan Awal Matematika Mahasiswa

\begin{tabular}{|c|c|c|c|c|c|}
\hline $\boldsymbol{n}_{\mathbf{1}}$ & $\boldsymbol{n}_{\mathbf{2}}$ & $\boldsymbol{n}_{\mathbf{1}}+\boldsymbol{n}_{\mathbf{2}}-\mathbf{1}$ & $\boldsymbol{F}_{\text {hit }}$ & $\boldsymbol{F}_{\mathbf{0 , 0 5}, \mathbf{2 5 5}}$ & $\begin{array}{c}\text { Keputusan } \\
\text { Uji }\end{array}$ \\
\hline 27 & 29 & 55 & 1,7285 & 4,00 & $\begin{array}{c}\text { Ho tidak } \\
\text { ditolak }\end{array}$ \\
\hline
\end{tabular}

Berdasarkan hasil uji keseimbangan diperoleh nilai $F_{\text {hit }}$ sebesar 1,7285 dan $F_{0,05,2,55}$ sebesar 4,00.Hal ini berarti keputusan uji keseimbangan terhadap data kemampuan awal matematika siswa adalah $H$ o tidak ditolak. Dengan demikian, disimpulkan bahwa populasi mempunyai kemampuan awal matematika yang sama.

\section{b. Deskripsi Data}

Dalam penelitian ini, data yang digunakan untuk menguji hipotesis meliputi data hasil belajar pada mata kuliah metode numerik.

Tabel 5. Deskripsi Skor Hasil Belajar Matematika pada MasingMasing Model Pembelajaran

\begin{tabular}{|l|c|c|c|c|c|}
\hline \multicolumn{1}{|c|}{ Model } & $\boldsymbol{n}$ & Min & Maks & Rerata & $\begin{array}{c}\text { Standar } \\
\text { Deviasi }\end{array}$ \\
\hline Group Investigation & 27 & 60 & 90 & 73,15 & 8,33 \\
\hline Discovery Learning & 29 & 55 & 85 & 66,51 & 20,33 \\
\hline
\end{tabular}

Berdasarkan tabel di atas dapat dilihat pada kelas yang menerapkan model pembelajaran group investigation berbasis problem solving memiliki nilai rata-rata postest yang lebih tinggi dari pada kelas yang menerapkan model pembelajaran discovery learning berbasis problem solving.

\section{c. Analisis Data}

Uji normalitas populasi ini menggunakan metode Lilliefors disajikan dalam Tabel.6 berikut.

Tabel 6. Hasil Uji Normalitas Populasi Terhadap Data Hasil Belajar Mahasiswa

\begin{tabular}{|c|c|c|c|c|}
\hline Kelas & $\boldsymbol{n}$ & $\boldsymbol{L}_{\boldsymbol{h i t}}$ & $\boldsymbol{L}_{\mathbf{0 , 0 5} \boldsymbol{n}}$ & Keputusan Uji \\
\hline Group Investigation & 27 & 0,1640 & 0,1730 & $\mathrm{H}_{0}$ diterima \\
\hline Discovery Learning & 29 & 0,1472 & 0,1610 & $\mathrm{H}_{0}$ diterima \\
\hline
\end{tabular}


Berdasarkan hasil uji normalitas populasi pada Tabel.6 terhadap data hasil belajar matematika siswa, sampel pada kelas discovery learning mempunyai nilai $L_{h i t}$ sebesar 0,1472 dan group investigation $L_{\text {hit }}$ sebesar 0, 1640. Hasil $L_{\text {hit }}$ yang diperoleh kurang dari $L_{0,05 ; n}$. Hal ini berarti pada taraf signifikansi 0,05 , keputusan uji normalitas populasi setiap sampel adalah $\mathrm{H}_{0}$ tidak ditolak. Dengan demikian, dapat disimpulkan bahwa sampel berasal dari populasi yang berdistribusi normal.

Dengan taraf signifikansi 0,05 , berikut hasil uji homogenitas variansi populasi menggunakan uji Bartlett disajikan pada Tabel 7.

Tabel 7. Hasil Uji Homogenitas Variansi Populasi Terhadap Data Kemampuan Awal Matematika Siswa

\begin{tabular}{|c|c|c|c|c|c|}
\hline Sampel & $\boldsymbol{k}$ & $\chi^{2}$ hit & $\chi^{2}{ }_{0,05 ; 2}$ & $\begin{array}{c}\text { Keputusan } \\
\text { Uji }\end{array}$ & Kesimpulan \\
\hline $\begin{array}{l}\text { Kelas Discovery dan } \\
\text { Group Investigation }\end{array}$ & 2 & 0,0001 & 5,9910 & $\begin{array}{c}H_{0} \text { tidak } \\
\text { ditolak }\end{array}$ & Homogen \\
\hline
\end{tabular}

Berdasarkan hasil uji homogenitas variansi populasi terhadap data hasil belajarmatematika siswa, diperoleh nilai $\chi^{2}$ hit sebesar 0,0001 dan $\chi_{0,05 ; 2}^{2}$ sebesar 5,9910 . Hai ini berarti pada taraf signifikansi 0,05 nilai $\chi^{2}$ hit kurang dari $\chi_{0,05 ; 2}^{2}$. Dengan demikian, $H_{\mathrm{o}}$ tidak ditolak dan diperoleh populasi-populasi yang dibandingkan mempunyai variansi yang sama (homogen).

Setelah data kedua sampel untuk kelas eksperimen I dan kelas eksperimen II yang diperoleh dari penelitian kemudian diuji dengan uji normalitas dan uji homogenitas. Hasil pengujian membuktikan bahwa sampel tersebut berdistribusi normal dan mempunyai varians yang homogen. Maka selanjutnya data tersebut dapat digunakan untuk pengujian hipotesis. Uji hipotesis dilakukan untuk melihat apakah terdapat perbedaan yang signifikan antara hasil belajar metode numerik pada masingmasing model pembelajaran.

Berdasarkan rumus uji $t$ yang digunakan dalam pengujian hipotesis dengan memperhatikan persyaratan yang ada, maka hasil analisis yang diperoleh yaitu harga numerik $t_{\text {hitung }}=3,0133$ dan $\mathrm{t}_{\text {tabel }}=1,960$ untuk dk $=\left(\mathrm{n}_{1}+\mathrm{n}_{2}-\right.$ 2) $=54$ dan taraf nyata $\alpha=0.05$ yang terdapat pada lampiran 9 . Apabila $t_{\text {hitung }}>t_{\text {tabel }}$, maka $\mathrm{H}_{0}$ ditolak, sehingga dapat disimpulkan bahwa penggunaan model pembelajaran group investigation berbasis problem 
solving lebih baik dari discovery berbasis problem solving.

Berdasarkan analisis data hasil penelitian, diperoleh hasil belajar siswa kelas group investigation berbasis problem solving lebih tinggi dibandingkan dengan kelas discovery learning berbasis problem solving, hal ini dikarenakan kelas group investigation berbasis problem solving memiliki banyak kesempatan untuk bertanya, mengemukakan pendapat, meningkatkan pemahaman dan keterampilan berkomunikasi antar siswa. Sedangkan pada kelas discovery learning berbasis problem solving proses pembelajarannya siswa menemukan sendiri konsep metode numerik, hal ini mengindikasikan bahwa penerapan model pembelajaran ini membuat siswa lebih cenderung takut untuk menjawab salah dari pertanyaan guru, sehingga keberanian mereka menjawab hampir tidak ada dan kesalahan pemahaman konsep sebelumnya. Inilah faktor yang membedakan hasil belajar siswa antara kelas eksperimen.

Dalam penelitian diperoleh data skor hasil belajar mahasiswa melalui tes evaluasi yang berbentuk essay sebanyak 5 item dapat dilihat pada lampiran 10. Di akhir pembelajaran, dilakukan tespada kedua kelas eksperimen tersebut untuk melihat seberapa besar peningkatan yang diperoleh mahasiswa selama proses belajar mengajar yang telah dilakukan. Dari hasil penelitian yang diperoleh, pada didapatkan nilai rata-rata tes. Dimana nilai ratarata tesuntuk kelas eksperimen I yang menerapkan model pembelajaran dan kelas eksperimen II yang menerapkan model pembelajaran berturut-turut adalah 73,10 dan 66,55. Perbandingan nilai teskedua kelas eksperimen dapat dilihat pada gambar di bawah ini.

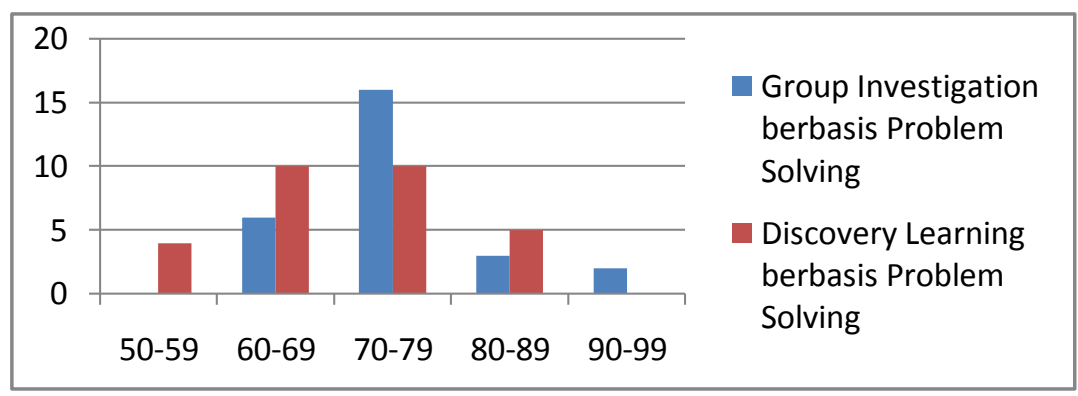

\section{Gambar 1. Perbandingan Nilai tes Kedua Kelas Eksperimen I dan Eksperimen II}


Perbandingan rata-rata skor hasil belajar mahasiswa yang menggunakan pembelajaran group investigation berbasis problem solvin dengan kelas discovery learning berbasis problem solving menunjukan bahwa rata-rata skor hasil belajar mahasiswa terlihat kelas eksperimen yang menggunakan model group investigation berbasis problem solving lebih tinggi dibandingkan dengan kelas discovery learning berbasis problem solving. Setelah diberikan tes, maka hasil penelitian mahasiswa menunjukan bahwa persentase hasil belajar dimasing-masing kelas eksperimen terdapat perbedaan. Dari semua aspek kognitif, dalam hal ini yaitu pengetahuan, pemahaman, aplikasi dan analisis. Model pembelajaran group investigation berbasis problem solving adalah sebuah model belajar kooperatif yang menitikberatkan pada kerja kelompok siswa sehingga setiap anggota bertanggung jawab terhadap penguasaan setiap komponen yang ditugaskan guru dengan sebaik-baiknya. Mahasiswa dapat menginvestigasi materi yang diberikan oleh dosen Pembelajaran kooperatif tipe group investigation merupakan salah satu tipe pembelajaran kooperatif yang menekankan pada struktur khusus yang dirancang untuk mempengaruhi pola interaksi siswa dan memiliki tujuan untuk meningkatkan penguasaan akademik. Setelah kelompok terbentuk dosen mengajukan beberapa pertanyaan yang harus dijawab tiap-tiap kelompok. Diberikan kesempatan tiap-tiap kelompok menemukan jawaban atas pertanyaan yang diberikan. Berdasarkan jawabanjawaban itu guru dapat mengembangkan diskusi lebih mendalam, sehingga mahasiswa dapat menemukan jawaban pertanyaan itu sebagai pengetahuan yang utuh.

Melalui penelitian ini diperoleh hasil bahwa terdapat perbedaan antara hasil belajar siswa yang diajarkan dengan menggunakan model pembelajaran group investigation berbasis problem solving dengan model pembelajaran discovery learning berbasis problem solving. Perbedaan tersebut ditunjukkan oleh distribusi rata-rata skor hasil belajar pada setiap item test antara kelas eksperimen.

\section{KESIMPULAN DAN SARAN}

Dari hasil penelitian dapat disimpulkan bahwa:

a. Pada kelas eksperimen I yang menerapkan model pembelajaran group investigation berbasis problem solving diperoleh nilai rata-rata hasil belajar sebesar 73,10 sedangkan pada kelas eksperimen II yang menerapkan discovery learning berbasis problem solving 
diperoleh nilai rata-rata postest sebesar 66,55.

b. Terdapat perbedaan yang signifikan antara hasil belajar siswa pada kelas yang menerapkan discovery learning berbasis problem solving dan kelas yang menerapkan model pembelajaran group investigation berbasis problem solving pada pokok bahasan metode numerik. Hasil belajar mahasiswa padapembelajaran group investigation berbasis problem solving lebih baik pada kelas yang menerapkan model discovery learning berbasis problem solving.

Dari hasil penelitian yang diperoleh, maka peneliti memberikan saran sebagai berikut:

a. Pada kegiatan pembelajaran dengan menerapkan model pembelajaran pembelajaran group investigation berbasis problem solving sebaiknya semua mahasiswa dalam satu kelompok harus memiliki sumber materi lebih banyak selain dari buku referensi yang berasal dari dosen.

b. Pada kegiatan model pembelajaran pembelajaran group investigation berbasis problem solving ketika menyelesaikan masalah sebaiknya siswa dipasangkan dengan teman yang tingkat kemampuannya berbeda atau heterogen supaya proses pembelajaran dapat berlangsung dengan lancar.

\section{DAFTAR PUSTAKA}

Hamdani. 2010. Strategi Belajar Mengajar. Bandung: Pustaka Setia.

Lee, K.H. \& Sriraman, B. 2010. Conjecturing via reconceived classical analogy. Columbia. J. of Educational Studies in Mathematics. 76 (2): 123140. Diunduh dari http://www.springerlink.com/ content pada 12 Juni 2015 pukul 22.00 WIB.

Setiawan, A. 2006. Pengantar Metode Numerik. PT Andi Offsett. Yogyakarta.

Silver, E. A. 2007. Fostering creativity through instruction rich mathematical problem solving and problem Solving. ZDM The International J. Of Mathematics Education, 29 (3): 75-80. Diunduh dari http://www.ejmste.com11 Juni 2015 pukul 10.00 WIB.

Thobroni, Muhammad. 2011. Belajar dan Pembelajaran. Yogyakarta: Ar-Ruz Media. 